\title{
Transient caloric restriction and cancer risk (The Netherlands)
}

\author{
Sjoerd G. Elias · Petra H. M. Peeters • \\ Diederick E. Grobbee · Paulus A. H. van Noord
}

Received: 28 July 2006/ Accepted: 14 September 2006

(C) Springer Science+Business Media B.V. 2006

\begin{abstract}
Over the past century, many animal experiments have shown that caloric restriction can reduce the risk of cancer, a finding that proved to be highly reproducible. Many papers have been published on its potential for human health, but until know little evidence is available on its actual effects in humans. In Utrecht, The Netherlands, we have been investigating the effects of the 1944-1945 Dutch famine on breast cancer risk factors and breast cancer risk, and paradoxically the relatively short-term famine seemed to be related to increased breast cancer risk in later life. One of the differences between the famine situation and the large body of evidence from animal experiments is the duration of caloric restriction. Almost all animal experiments investigated sustained caloric restriction and information on the effects of short-term transient caloric restriction is very scarce. A search in the literature identified some animal experiments on shortterm transient caloric restriction and these seemed to be at least supportive to the famine findings. Because caloric restriction in humans for preventive health measures would be mostly short-term, it is important to extend animal research on short-term caloric restriction.
\end{abstract}

Keywords Caloric restriction · Transient - Cancer . Risk · Famine · Human

S. G. Elias $(\bowtie)$ · P. H. M.Peeters · D. E. Grobbee

P. A. H.van Noord

Julius Center for Health Sciences and Primary Care, University Medical Center Utrecht, P.O. Box 85500, 3508

GA Utrecht, The Netherlands

e-mail: s.elias@umcutrecht.nl
During the 20th century, a large body of experimental evidence has been accrued signifying that caloric restriction protects against cancer. Rodent data are abundant and consistently show (i) that caloric restriction lowers the incidence of a variety of spontaneous as well as induced or transplanted tumours; (ii) that this effect is directly proportional to the amount of caloric restriction; (iii) that the effects can largely be ascribed to caloric restriction per se, and not merely to the decrease in one or more dietary components; (iv) that caloric restriction initiated in early life as well as in later life is effective in cancer prevention; (v) that caloric restriction prolongs life [1-5]. A pooled quantification of the inhibitory effects of caloric restriction on spontaneous mammary tumour incidence in mice showed that caloric restriction lowered the incidence with 55\% [6].

Preliminary reports on energy restriction in nonhuman primates appear to be consistent with findings in rodents $[7,8]$. What about humans? Obviously, this is difficult to investigate, but can lead to important insights in cancer aetiology and to opportunities for prevention. The 1944-1945 Dutch famine, a relatively short severe famine during World War II [9, 10], could shed some light on this issue, and has been used before as an "experiment of history" [11-13].

During the past years, we have conducted several studies on the effects of the 1944-1945 Dutch famine on breast cancer risk factors and breast cancer risk in Utrecht, The Netherlands. For these studies we used data on women who were between 2 and 33 years of age during the famine. Therefore we were not only able to investigate the long-term effects of caloric restriction, but could also relate those effects to specific time-windows in female development. Women were 
classified to their degree of famine experience on an individual basis, leading to a three-point famine score ('absent', 'moderate', or 'severe' exposure) that enabled dose-response evaluation [14].

In brief, we found that the famine is associated with subsequent reduced reproductive ability in women who were exposed during childhood. This is manifested by decreased chance of childbirth and an earlier mean age at menopause $[15,16]$. Strikingly, research on moderate early life diet restriction in Drosophila melanogaster by Tu and Tatar showed also a decrease in adult fecundity [17]. Furthermore, we found that hormone concentrations, measured postmenopausal, seem to be affected by the famine with increases in sex-steroid as well as insulin-like growth factor (IGF)-I and IGF binding protein (IGFBP)-3 levels (resulting in unaffected IGF-I to IGFBP-3 ratios) [18, 19]. All our observations showed a dose-response to degree of famine exposure, with smaller but still observable associations in those moderately exposed.

With regard to breast cancer risk, the associations between the famine and the reproductive system would suggest a protective effect of the famine [20]. However, the associations with hormone concentrations would suggest the contrary [21, 22], with the exception of increased IGFBP-3 that may relate to decreased breast cancer risk [23].

When we actually determined the effect of famine on breast cancer risk in this population, we found that the famine is related to increased risk, again in a dose response manner-a finding that was stronger in women who were children during the 1944-1945 winter [24]. Body mass index at later ages did not confound this relation nor modified it (last data unpublished), suggesting that catch-up growth after the famine did not play an important role. Total cancer risk, exclusive of breast cancer, seemed not to be affected by the famine [25], which does not preclude that famine may have affected risk of specific types of cancer, but the numbers in our study are presently too small for analysis with more detail. Another famine study by Dirx et al. on breast cancer risk could not detect a protection against breast cancer from the famine either, and if anything, showed a moderate increase in risk in women that were exposed at young ages [11]. In addition, Dirx et al. showed that the famine was, nonsignificantly, associated with increased prostate cancer and decreased colon cancer risk $[12,13]$. In these studies, Dirx et al. used place of residence as a measure of famine exposure whereas we used individual exposure data, based on recall.

These findings are not in line with the animal experiments consistently showing caloric restriction to prevent cancer. Several differences between the usually adopted caloric deprivation strategy in animal experiments and the 1944-1945 Dutch famine may explain these differences, such as the amount of restricted calories. The exact degree of caloric restriction during the 1944-1945 Dutch famine is difficult to ascertain, but rations dropped to about $30 \%$ of desired norms for adults and to about $50 \%$ for young children. The relative amounts of carbohydrates, fats and proteins remained more or less balanced, and supplementations to the rations were sometimes clandestinely available. Young children were relatively protected within families and by charity organisations $[9,10]$. Although the amount of caloric restriction during this famine is larger than usually adopted in animal experiments, tumour incidence has been shown to decrease proportionally to degree of caloric restriction in animal experimental settings, amounting to an estimated $62 \%$ tumour reduction with $53 \%$ caloric restriction [2]. Therefore, it is unlikely that differences in the amount of caloric restriction explain the contradictory results of the famine studies and the animal experiments.

More notably, during the Dutch famine people were transiently exposed for a relatively short duration of time (6 months) [9, 10]. Therefore, this "experiment of history"-as most current famines due to crop disaster or war-is only similar to experiments in rodents that studied short-term caloric restriction followed by ad libitum feeding, whereas the vast majority of these studies investigated dietary interventions that were sustained throughout the animals entire live.

We were able to identify eight animal experiments that investigated transient and mostly short-term caloric restriction, where after animals were allowed to eat at will [26-33]. Two of these experiments studied the effect of caloric restriction for different time periods during and after the chemically induction of breast cancer in female rats [28, 31]. Sustained caloric restriction dramatically decreased tumour incidence: from $50 \%$ in the ad libitum group to $20 \%$ in the continuously restricted group [31]. It also seemed that caloric restriction during tumour initiation-from 1 week before until 1 week after 7,12-dimethylbenz$[\alpha]$ anthracene administration - potently reduced mammary tumour development [28]. However, restriction for any period after tumour initiation followed by ad libitum feeding, if anything, showed no substantial effect, and could even lead to increased breast cancer risk [28]. Furthermore, Kritchevsky noticed that when rats were returned from restricted to ad libitum feeding this resulted in hyperphagia, accelerated weight gain, 
transient mammary hypertrophy, and enhanced tumour growth [31].

Four other experiments investigated the effect of caloric restriction for different periods on, amongst others, spontaneous overall tumour incidence in rats $[26,27,30]$, and mice [29]. Again, these studies showed that sustained caloric restriction throughout life lowered cancer risk substantially. However, caloric restriction confined to early life did either not affect cancer risk [30], or actually seemed to increase it [26, 27, 29]. This feeding strategy did not materially increase lifespan, so this cannot explain the observed increase in cancer risk. The study of Cheney et al. in female mice provides some evidence that caloric restriction confined to mid-life may also eventually lead to increased cancer burden [29].

Recently, interest was rekindled with two more studies on prolonged but transient caloric restriction and 1-methyl-1-nitrosaurea induced mammary carcinogenesis in rats $[32,33]$. These studies both show that upon refeeding tumour incidence increased.

The disparity between our findings in humans after caloric restriction during a short and severe famine and the abundant literature on sustained caloric restriction and cancer risk in rodents may be ascribed to differences in exposure duration, as is corroborated by the abovementioned animal studies on transient caloric restriction that are in line with the famine observations.

From a biological point of view, it may not be surprising that a short and transient period of caloric restriction in early life may increase human cancer risk. During caloric restriction, a range of responses can be seen, most of which could be directly beneficial to overall cancer risk but are unlikely to be of importance once the restriction is discontinued. Proliferation of cells is reduced with both increased rates of apoptosis together with decreased DNA synthesis and increased DNA repair, limiting the number of preneoplastic lesions. Oxidative stress is reduced, resulting in decreased reactive oxygen species that can damage DNA. Furthermore, of interest to hormone associated tumours, levels of a number of hormones and growth factors are altered during caloric restriction: glucocorticoids are increased whereas concentrations of IGF-I (and to a lesser extent IGFBP-3 resulting in decreased bioavailability of IGF-I), insulin, prolactin, estrogens and leptin are decreased [3-5, 34-36].

Changes in leptin levels can interfere with sexual maturation [37, 38], a period in development during which the Dutch famine showed the largest impact on breast cancer risk in our study. It could be that the hypothalamo-pituitary axis, which is not matured in girls until a few years after menarche when regular menses are established [39], has erroneously adapted to the period of paucity, leading to inappropriate setlevels of hormones that could relate to hormone associated cancers [18, 19]. Such erroneous adaptations, also described as a "thrifty phenotype" [40], are the subject of the "foetal and infant origins of adult disease" hypothesis by Barker and colleagues [41]. Evidence is mounting that such long-lasting effects indeed exist and may contribute considerably to later health [42]. The potential involvement of the hypothalamo-pituitary axis herein has been recognised [43].

In conclusion, the general notion that caloric restriction prevents cancer needs some amendment, even for rodents. Evidence is strong that during caloric restriction, cancer risk is decreased proportionally to the amount of restriction, and such interventions can be effective whether started in early life or later. However, a short and transient period of restriction followed by a "normal" diet does not show such effects and could actually be detrimental.

Thompson et al. made a similar plea. If humans are advised to eat less as a means to prevent cancer, this would probably result in repetitive periods of weight loss followed by periods of weight gain. He warned that such weight cycling may be associated with a modest acceleration of the carcinogenic response [44].

Animal experiments on short-term interventions or weight-cycling diets are scarce and their results yet inconclusive. Such animal experiments are nevertheless highly relevant and need further investigation before any preventive strategy is researched in experimental settings, or actually adopted, in humans, as short-term interventions are the most feasible for the human situation but may bring along considerable hazards. It would be of importance to see if our observations can be replicated in such animal experiments and in human studies making use of other famine episodes, e.g. the 1959-1961 Chinese famine [45]. Other human studies may involve for instance children from countries with poor nutrition that are adopted by families in economically prosperous countries. These children have been exposed to adverse nutritional circumstances at young ages for a clearly demarcated period followed by nutritional abundance (in contrast to immigration studies of for example Japanese women to the United States who gradually adapt, often partly, to a Western lifestyle). Indian girls adopted in Sweden have for example been shown to reach menarche at younger ages compared to Indian standards [46]. It would be intriguing to see whether other physiologic changes occur in these children, e.g. with regard to hormonal levels. 
Furthermore, studies on cancer risk in patients with anorexia nervosa are also of interest. Two studies have reported on the topic and found a decreased risk of breast cancer [47, 48]. The generalisability of these observations is however troubled as factors underlying this disease may contribute to the decrease in breast cancer risk, so this may not merely be ascribed to a decreased caloric intake per se.

Currently, the relation between famine exposure in early life and risk of other types of cancer than that of the breast is largely unknown. It would be valuable to further investigate these relations to see whether associations are different between cancer types, e.g. comparing hormone to non-hormone associated cancer types. This would give further insight into whether general mechanisms in human cancer aetiology are involved or whether adaptation of hormonal axes leading to harmful hormone concentrations is the potential culprit.

Acknowledgment This research is financially supported by Dutch Cancer Society grant UU-2000-2314 to P.A.H. van Noord.

\section{References}

1. Weindruch R, Walford RL (1988) The retardation of aging and disease by dietary restriction. Charles C Thomas Publisher, Springfield, Illinois

2. Albanes D (1987) Total calories, body weight, and tumor incidence in mice. Cancer Res 47:1987-1992

3. Kritchevsky D (1997) Caloric restriction and experimental mammary carcinogenesis. Breast Cancer Res Treat 46:161167

4. Hursting SD, Lavigne JA, Berrigan D, Perkins SN, Barrett JC (2003) Calorie restriction, aging, and cancer prevention: mechanisms of action and applicability to humans. Annu Rev Med 54:131-152

5. Pariza W (1987) Dietary fat, calorie restriction, ad libitum feeding, and cancer risk. Nutr Rev 45:1-7

6. Dirx MJ, Zeegers MP, Dagnelie PC, van den Bogaard T, van den Brandt PA (2003) Energy restriction and the risk of spontaneous mammary tumors in mice: a meta-analysis. Int $\mathbf{J}$ Cancer 106:766-770

7. Lane MA, Black A, Handy A, Tilmont EM, Ingram DK, Roth GS (2001) Caloric restriction in primates. Ann N Y Acad Sci 928:287-295

8. Roth GS, Ingram DK, Lane MA (1999) Calorie restriction in primates: will it work and how will we know? J Am Geriatr Soc 47:896-903

9. de Jong L (1981) Het Koninkrijk der Nederlanden in de Tweede Wereldoorlog. (The Kingdom of the Netherlands in the Second World War (In Dutch)). General State Printing Office, The Hague

10. Burger GCE, Sandstead HR, Drummond JC (1948) Malnutrition and starvation in Western Netherlands, September 1944 to July 1945. Part I and II. General State Printing Office, The Hague
11. Dirx MJ, van den Brandt PA, Goldbohm RA, Lumey LH (1999) Diet in adolescence and the risk of breast cancer: results of the Netherlands Cohort Study. Cancer Causes Control 10:189-199

12. Dirx MJ, van den Brandt PA, Goldbohm RA, Lumey LH (2001) Energy restriction in childhood and adolescence and risk of prostate cancer: results from the Netherlands Cohort Study. Am J Epidemiol 154:530-537

13. Dirx MJ, van den Brandt PA, Goldbohm RA, Lumey LH (2003) Energy restriction early in life and colon carcinoma risk: results of The Netherlands Cohort Study after 7.3 years of follow-up. Cancer 97:46-55

14. Elias SG, van Noord PA, Peeters PH, den Tonkelaar I, Grobbee DE (2002) The 1944-1945 Dutch famine and age at natural menopause-the value and validity of individual exposure assessment. IARC Sci Publ 156:311-313

15. Elias SG, van Noord PA, Peeters PH, den Tonkelaar I, Grobbee DE (2003) Caloric restriction reduces age at menopause: the effect of the 1944-1945 Dutch famine. Menopause 10:399-405

16. Elias SG, van Noord PA, Peeters PH, den Tonkelaar I, Grobbee DE (2005) Childhood exposure to the 1944-1945 Dutch famine and subsequent female reproductive function. Hum Reprod 20:2483-2488

17. Tu MP, Tatar M (2003) Juvenile diet restriction and the aging and reproduction of adult Drosophila melanogaster. Aging Cell 2:327-333

18. Elias SG, Onland-Moret NC, Peeters PH, et al (2004) Urinary endogenous sex hormone levels in postmenopausal women after caloric restriction in young adulthood. $\mathrm{Br} \mathrm{J}$ Cancer 90:115-117

19. Elias SG, Keinan-Boker L, Peeters PH, et al (2004) Long term consequences of the 1944-1945 Dutch famine on the insulin-like growth factor axis. Int J Cancer 108:628-630

20. Kelsey JL, Gammon MD, John EM (1993) Reproductive factors and breast cancer. Epidemiol Rev 15:36-47

21. Fürstenberger G, Senn HJ (2002) Insulin-like growth factors and cancer. Lancet Oncol 3:298-302

22. The endogenous hormones and breast cancer collaborative group (2002) Endogenous sex hormones and breast cancer in postmenopausal women: reanalysis of nine prospective studies. J Natl Cancer Inst 94:606-616

23. Schedlich LJ, Graham LD (2002) Role of insulin-like growth factor binding protein-3 in breast cancer cell growth. Microsc Res Tech 59:12-22

24. Elias SG, Peeters PH, Grobbee DE, van Noord PA (2004) Breast cancer risk after caloric restriction during the 19441945 Dutch famine. J Natl Cancer Inst 96:539-546

25. Elias SG, Peeters PH, Grobbee DE, van Noord PA (2005) The 1944-1945 Dutch famine and subsequent overall cancer incidence. Cancer Epidemiol Biomarkers Prev 14:1981-1985

26. Ross MH, Bras G (1971) Lasting influence of early caloric restriction on prevalence of neoplasms in the rat. J Natl Cancer Inst 47:1095-1113

27. Nolen GA (1972) Effect of various restricted dietary regimens on the growth, health and longevity of albino rats. J Nutr 102:1477-1493

28. Sylvester PW, Aylsworth CF, Van Vugt DA, Meites J (1982) Influence of underfeeding during the "critical period" or thereafter on carcinogen-induced mammary tumors in rats. Cancer Res 42:4943-4947

29. Cheney KE, Liu RK, Smith GS, Meredith PJ, Mickey MR, Walford RL (1983) The effect of dietary restriction of varying duration on survival, tumor patterns, immune function, and body temperature in $\mathrm{B} 10 \mathrm{C} 3 \mathrm{~F} 1$ female mice. J Gerontol 38:420-430 
30. Maeda H, Gleiser CA, Masoro EJ, Murata I, McMahan CA, Yu BP (1985) Nutritional influences on aging of Fischer 344 rats: II. Pathology. J Gerontol 40:671-688

31. Kritchevsky D, Welch CB, Klurfeld DM (1989) Response of mammary tumors to caloric restriction for different time periods during the promotion phase. Nutr Cancer 12:259-269

32. Zhu Z, Jiang W, Thompson HJ (2002) An experimental paradigm for studying the cellular and molecular mechanisms of cancer inhibition by energy restriction. Mol Carcinog 35:51-56

33. Zhu Z, Jiang W, McGinley J, Wolfe P, Thompson HJ (2005) Effects of dietary energy repletion and IGF-1 infusion on the inhibition of mammary carcinogenesis by dietary energy restriction. Mol Carcinog 42:170-176

34. Albanes D (1987) Caloric intake, body weight, and cancer: a review. Nutr Cancer 9:199-217

35. Weindruch R, Keenan KP, Carney JM, et al (2001) Caloric restriction mimetics: metabolic interventions. J Gerontol A Biol Sci Med Sci 56(1):20-33

36. Kaaks R, Lukanova A (2001) Energy balance and cancer: the role of insulin and insulin-like growth factor-I. Proc Nutr Soc 60:91-106

37. Farooqi IS (2002) Leptin and the onset of puberty: insights from rodent and human genetics. Semin Reprod Med 20:139-144

38. Farooqi IS, Jebb SA, Langmack G, et al (1999) Effects of recombinant leptin therapy in a child with congenital leptin deficiency. N Engl J Med 341:879-884
39. Harlow SD, Ephross SA (1995) Epidemiology of menstruation and its relevance to women's health. Epidemiol Rev 17:265-286

40. Wells JC (2003) The thrifty phenotype hypothesis: thrifty offspring or thrifty mother? J Theor Biol 221:143-161

41. Barker DJ (1990) The fetal and infant origins of adult disease. BMJ 301:1111

42. Barker DJ (1998) Mothers, babies and health in later life, 2nd edn. Churchill Livingstone, Edinburgh

43. Gluckman PD, Hanson MA (2004) Living with the past: evolution, development, and patterns of disease. Science 305:1733-1736

44. Thompson HJ, Zhu Z, Jiang W (2002) Protection against cancer by energy restriction: all experimental approaches are not equal. J Nutr 132:1047-1049

45. St Clair D, Xu M, Wang P, et al (2005) Rates of adult schizophrenia following prenatal exposure to the Chinese famine of 1959-1961. JAMA 294:557-562

46. Proos LA, Hofvander Y, Tuvemo T (1991) Menarcheal age and growth pattern of Indian girls adopted in Sweden. I. Menarcheal age. Acta Paediatr Scand 80:852-858

47. Mellemkjaer L, Emborg C, Gridley G, et al (2001) Anorexia nervosa and cancer risk. Cancer Causes Control 12:173-177

48. Michels KB, Ekbom A (2004) Caloric restriction and incidence of breast cancer. JAMA 291:1226-1230 